\title{
Optimizing Penile Length in Patients Undergoing Partial Penectomy for Penile Cancer: Novel Application of the Ventral Phalloplasty Oncoplastic Technique
}

\author{
Jared J. Wallen¹, Adam S. Baumgarten¹, Tim Kim², Tariq S. Hakky¹, Rafael E. Carrion¹, Philippe E. \\ Spiess $^{2}$ \\ ${ }^{1}$ Department of Urology, University of Southern Florida, USA, ${ }^{2}$ Department of Genitourinary Oncology, \\ Moffitt Cancer Center, USA
}

\section{ABSTRACT}

The ventral phalloplasty (VP) has been well described in modern day penile prosthesis surgery. The main objectives of this maneuver are to increase perceived length and patient satisfaction and to counteract the natural 1-2 cm average loss in length when performing implantation of an inflatable penile prosthesis. Similarly, this video represents a new adaptation for partial penectomy patients. One can only hope that the addition of the VP for partial penectomy patients with good erectile function will increase their quality of life. The patient in this video is a 56 -year-old male who presented with a $4.0 \times 3.5 \times 1.0 \mathrm{~cm}$, pathologic stage T2 squamous cell carcinoma of the glans penis. After partial penectomy with VP and inguinal lymph node dissection, pathological specimen revealed negative margins, 3/5 right superficial nodes and 1/5 left superficial nodes positive for malignancy. The patient has been recommended post-operative systemic chemotherapy (with external beam radiotherapy) based on the multiple node positivity and presence of extranodal extension. The patient's pre-operative penile length was 9.5 $\mathrm{cm}$, and after partial penectomy with VP, penile length is $7 \mathrm{~cm}$.

\section{ARTICLE INFO}

Available at:

www.brazjurol.com.br/videos/september_october_2014/Spiess_708_709video.htm

Int Braz J Urol. 2014; 40 (Video \#13): 708-709

Submitted for publication:

May 10, 2014

Accepted after revision:

July 15, 2014
Correspondence address:

Philippe E. Spiess, MD

Associate Member, Department of

Genitourinary Oncology

Moffitt Cancer Center

12902 Magnolia Drive, Office 12538

Tampa, FL 33612

Fax: + 1813 745-8494

E-mail: philippe.spiess@moffitt.org 


\section{EDITORIAL COMIMENT}

In the video by Dr. Wallen JJ and colleagues, an elegant way to improve the cosmesis and perceived penile length of patients undergoing partial penectomy for penile cancer is presented. Previous reports $(1,2)$ demonstrated its utility in penile prosthetic surgery.

\section{REFERENCES}

1. Carrion R: Ventral phalloplasty. J Sex Med. 2010;7:2914-7.

2. Hakky TS, Suber J, Henry G, Smith D, Bradley P, Martinez $D$, Carrion RE. Penile enhancement procedures with simultaneous penile prosthesis placement. Adv Urol. 2012;2012:314612.
Partial penectomy gives a good local control of the cancer, but with a potential effect on self-image.

This technique gives the opportunity to improve cosmesis with a perceived increase length that will help on self-image.
Jose Jaime Correa, MD

Urologic Oncology Department Hospital Pablo Tobon Uribe Medellin, Colombia E-mail: jocorreao@uces.edu.co 